\title{
Editorial
}

\section{ESTO SE ACABA SEÑORES}

Hace alrededor de un año atrás, aún bajo la presidencia del Dr. Sergio Cerda San Martín, empezó a conversarse en el seno del Directorio de la Sociedad de Anestesiología de Chile la posibilidad de transformar la Revista Chilena de Anestesia a formato único digital. Nunca se le comunicó nada oficial a los Editores ni al Consejo Editorial, pero era algo que se notaba en el aire. Escuché frases informales como "tenemos que conversar sobre la Revista" o "los vamos a citar a una reunión del Directorio", pero finalmente nada ocurrió.

Para tener una idea de qué argumentar en una eventual reunión, quise escuchar la apreciación de los más importantes líderes de opinión de nuestra especialidad (Maestros de la Anestesiología, ex Editores de la Revista, Past Presidents de nuestra Sociedad, miembros del Consejo Editorial y algunos probables futuros Maestros), exceptuando a los actuales miembros del Directorio.

Personalmente yo tengo algunos prejuicios en relación a la digitalización total de la Revista, pues creo que todo lo que no queda en papel es volátil y una vez en el ciberespacio también puede perderse por razones técnicas o vandálicas. Sin embargo, soy de una generación en que este prejuicio puede ser generalizado.

Como es sabido, desde hace muchos años nuestra Revista también puede verse en formato digital, con links a vídeos, de modo que no es ninguna novedad tenerla en esta forma. Además, hemos logrado algunos adelantos tecnológicos:

- Visibilidad y acceso para computadores de escritorios, teléfonos inteligentes (Android y OSX) y tabletas.

- Estadísticas básicas de visitas.

- Accesibilidad con códigos QR.

- Herramientas para compartir en Facebook, Twitter, correo electrónico y otros sistemas de redes sociales.

A pesar de todo, este sistema no funciona. Recibo innumerables reclamos sobre la ineficiente actualización de la versión digital de la revista, lo que me preocupa, pues mi nombre aparece como editor responsable de la versión digital. Me consta que las versiones en pdf están inmediatamente disponibles al entregarse la versión física de la revista, sin embargo, la actualización es muy posterior. En la actualidad, sólo son accesibles los ejemplares desde el Vol. 41 - $\mathrm{N}^{\mathrm{o}} 1$ - Abril 2012 hasta el Vol. 42 - $\mathrm{N}^{\mathrm{o}}$ 2 - Agosto 2013, porque sistemáticamente tengo que enviar artículos a quienes los requieren, especialmente los propios autores. De más está recordar que durante el período 2009-2011, siendo Secretario de la Sociedad de Anestesiología de Chile el Dr. David Castro, se dio el trabajo personal de ordenar y escanear números antiguos de la Revista Chilena de Anestesia, para que estuvieran a disposición de los socios en la página web, trabajo que no se ve reflejado hoy en nuestra versión digital.

Un problema aparte es la demora en el reparto de la versión física, que tiene que ver con múltiples factores y en la que se ha diseñado diferentes estrategias para lograr una mejor eficacia en la entrega. Como mejor ejemplo, yo mismo no he recibido por correo el ejemplar dejado en marzo de este año en la secretaría de la Sociedad y una pequeña encuesta realizada entre socios cercanos está completamente en consonancia con este hecho. Desde hace unos cuatro años, se optó por distribuir la revista vía correo al domicilio. Esto agregó un costo extra por número de la Revista de aproximadamente $\$ 800.000$, medida que aunque en un principio fue bien evaluada por los socios, tiene el inconveniente que hay un número importante de ejemplares que regresan a la sede de la $\mathrm{SACH}$, por problemas en el domicilio del receptor debido a la mala actualización de las direcciones de los socios y otras causas.

Al contarle al Dr. Jorge Urzúa, uno de nuestros Maestros más destacados, lo inminente que era la digitalización total de la Revista me escribió textualmente: "Sería la muerte de la Revista el hacerla solo digital. He visto desde hace décadas los anuncios apocalípticos de la muerte del papel y el crecimiento de revistas digitales (muchas de ellas bien malitas), pero la revista que se mira, se lee en las partes que a uno le interesan, y luego se atesora, pienso que es parte de la esencia de la publicación científica. A lo mejor estoy muy obsoleto. Algunos de los investigadores de esta facultad creen que hay que cerrar las colecciones en papel e ir a $100 \%$ digital; creo que están obnubilados por el optimismo enloquecido del progreso y del cambio".

Como la obsolescencia a la que se refería el Dr. Urzúa es cercana a la mía, pues no son muchos años los que nos separan, tuve la impresión de que las respuestas iban a estar divididas en relación a la edad de los consultados: los "subsetenta-sesenta" y los 
"subcincuenta-cuarenta", sin embargo, no fue así. En forma casi anónima, resumiré las opiniones de algunos de los consultados:

- "Estamos viviendo tiempos de cambios en todo aspecto y la accesibilidad, disponibilidad rápida y portabilidad, son aspectos importantes a considerar. La calidad no está en discusión ya que no tiene por qué cambiar y si cambia debe ser para mejor. A diario veo como las generaciones jóvenes (y no tan jóvenes) leen y buscan literatura médica casi exclusivamente en formato digital (revistas, libros, manuales, etc.). Ya casi nadie tiene tiempo para ir a una biblioteca o espacio para portar o guardar revistas o libros. El formato digital permite acceder fácil y rápidamente a un artículo desde un computador, ordenar varios artículos en una carpeta por tema, facilitar la preparación de una presentación y además nos permite ahorrar dinero y papel". (La opinión de una persona "subcincuenta-cuarenta", preocupada por el medio ambiente).

- Concordando con la opinión anterior, otro miembro del mismo grupo era enfático en opinar que "el formato digital llegó para quedarse y, definitivamente, la calidad no está determinada por éste".

- Un partidario más radical de la digitalización, y con datos sobre la mesa, expresó que los costos de impresión y distribución de los 4 números anuales de la Revista habían sido de \$ 11.000 .000 el último año.(Averiguando posteriormente, pude comprobar que las cifras no son tan altas). Los laboratorios y empresas relacionadas tienen cada vez menos interés en colocar avisos en medios gráficos y más interés en colocarlos en medios digitales, lo cual ha hecho que la brecha entre lo que se gasta y lo que se recibe sea cada vez más amplia. El recurso digital per- mite no sólo una presentación de primer nivel, si no también alternativas como la incorporación de vídeos que podrían hacer más atractiva la publicación de revisiones y casos clínicos. La idea de digitalizar la revista no considera subirla a la página web de la forma simple en que se hace ahora, sino que a cada socio le llegue a su correo vía un newsletter, en el que pueda desplegar todo el contenido. Implementar este mecanismo requiere el diseño de una página (aproximadamente $\$ 3.000 .000$ por una vez) y luego el pago de la distribución (aproximadamente \$ 2.000.000 por año).(Cifras que tampoco están lisitadas o por escrito en ningún documento).

- Saliéndose un poco del esquema de este grupo, un Past President opinaba estar de acuerdo con lo que plantea el Dr. Urzúa respecto a la posible desaparición de la Revista y a la importancia de la publicación en papel. Sin embargo, no veía el inconveniente (tal vez económico) para que existan las dos formas. De este modo, el formato electrónico sería una complementación y no una forma de reemplazo, que tendrá muy probablemente impacto en la cantidad de revistas impresas pero que facilitará la difusión de los contenidos.

- Relacionado también con la parte económica, uno de los consultados hizo la observación de que si el problema eran los costos, en otras Sociedades se hace la diferencia en el valor anual a pagar según el deseo o no de contar con la versión en papel de la Revista. El ideal sería contar con una aplicación de la revista (para teléfono inteligente o tableta) de la versión digital, y ésta a su vez con links a la página web de la Sociedad.

- Aunque creyendo que la cosa iba por lo digital, también una posición ecléctica la tomó uno de los más pragmáticos miembros del grupo con-

\begin{tabular}{|c|c|c|c|}
\hline \multirow[b]{2}{*}{ Pro } & Papel & Digital & Mixto \\
\hline & $\begin{array}{l}\text { - Romanticismo } \\
\text { - Sobrevivencia frente a crisis } \\
\text { energética } \\
\text { - Control de socios } \\
\text { - Desincentiva piratería } \\
\text { - Público cautivo }\end{array}$ & $\begin{array}{l}\text { - Ubicuidad } \\
\text { - Acceso internacional (pilar funda- } \\
\text { mental para indexar) } \\
\text { - Contenido adicional (vídeos, proto- } \\
\text { colos, etc.) } \\
\text { - Menor costo } \\
\text { - Financiamiento: posibilidad de } \\
\text { publicidad más dinámica } \\
\text { - Está de moda }\end{array}$ & $\begin{array}{l}\text { - Lo mejor de ambos } \\
\text { mundos } \\
\text { - Ya se está haciendo }\end{array}$ \\
\hline & Papel & Digital & Mixto \\
\hline Contra & $\begin{array}{l}\text { - Poco ecológico } \\
\text { - Nuevas generaciones prefieren lo } \\
\text { electrónico } \\
\text { - Caro } \\
\text { - En contra de la tendencia mundial }\end{array}$ & $\begin{array}{l}\text { - Piratería } \\
\text { - ¿Percepción de menos acuciosidad } \\
\text { en selección de artículos? } \\
\text { - ¿Papel es requisito para Indexa- } \\
\text { ción? }\end{array}$ & $\begin{array}{l}\text { - Caro (imprenta }+ \text { servi- } \\
\text { dor web) }\end{array}$ \\
\hline
\end{tabular}


sultado, que se dio la molestia de hacer una especie de Pro/Con con el fin de facilitar la toma de decisiones:

- El último miembro de este subgrupo opinaba que, querámoslo o no los que somos amantes del papel, lo digital es lo que viene (técnicamente ya vino hace tiempo). "No tengo el dato de revistas médicas, pero de las otras, incluyendo periódicos y la famosa Enciclopedia Británica, las versiones en papel ya pasaron a la historia. Personalmente los pdf los leo en el celular o tableta, a veces en el computador. Si por cualquier razón, veo la necesidad, imprimo sólo el paper en cuestión. La lista de libros para lectura de vacaciones da como para dos vidas más... Lo más importante es que los pdf (y html) que se publiquen sean indexables y buscables, para facilitar encontrar la información. No hay nada peor que tratar de buscar algo y no poder encontrarlo, sabiendo que existe. Tal vez deberíamos incorporar los famosos Tags, tan de moda en twitter, facebook y todo sitio online que se precie de bueno, que hacen más fácil encontrar grupos de publicaciones con el mismo tema."

Todo iba bien hasta ahí, cuando empezó a opinar el grupo de mayorcitos (léase aquéllos que se aproximaban más a los que habíamos tratado de obsoletos):

- "La verdad es que fuera de lo bonito que resulta tener una colección completa, o más o menos completa de una revista, la "utilidad" real de esta modalidad se ha perdido. Estoy en mi oficina, y miro sobre el escritorio un par de revistas que me llegan de USA, y hay números aún sin abrir. Prefiero ir al computador, y bajarlas desde nuestra biblioteca. En la actualidad todos andamos trayendo algún elemento electrónico que permite acceder a las páginas de las revistas."

- "Aunque me siento un asiduo consultor y lector de las publicaciones digitales de anestesia, soy un convencido que disponer de las publicaciones impresas es invaluable. A mi parecer, leer desde la pantalla del computador u otros medios es cansador, las impresiones de los pdf's suelen hacerse en papeles de mala calidad, los archivos se pierden (o al menos a mí me ocurre). No hay como leer pausadamente desde la revista original. Tengo claro que resulta más fácil, más barato, más accesible, más cómodo y ocupa mucho menos espacio la publicación digital, pero a pesar de ello, conservo las revistas de la Sociedad desde 1980. Disponer de las revistas en las diferentes bibliotecas médicas también me parece importante, y antes de tomar una decisión definitiva, consultaría la opinión de los bibliotecarios de los centros formadores, universidades y hospitales. ¿Una edición digital exclusiva afectará la calidad de nuestra publicación? ¿Tendrá algún impacto y podrá eventualmente ser indexada?".

- "El mantener la calidad y periodicidad de la Revista no se vería afectada por el formato digital. Además, hasta donde he averiguado, para lograr indexar la revista (que es una de nuestras metas), no es requisito que se edite en papel. En cuanto al formato digital, creo que se debería lograr lo que tienen las revistas ISI (Anestesia \& Analgesia, Pediatric Anesthesia, etc) en cuanto a clave, sistema de acceso, números disponibles, formato, etc. Entiendo lo difícil que puede ser cambiar la historia de la Sociedad; tal vez podría ayudar realizar una muy breve encuesta on-line a los socios sobre qué formato prefieren, en un período limitado de tiempo. Podría ayudar en tiempos de democracia y consultas".

- A pesar de unirse a los "nostálgicos" del pasado, uno de los consultados reconocía que desde que tenía una tableta, sus visitas a las librerías habían casi desaparecido y la lista de libros digitales "para las vacaciones" crecía interminablemente. Es difícil encontrar a un colega (desde residentes a "adultos mayores") con una revista médica en las manos, en cambio todos en sus dispositivos digitales tienen bibliotecas completas, perfectamente ordenadas, que ocupan muy poco espacio, son fácilmente trasportables y consumen muy pocos recursos naturales. Finalmente planteaba que sobre todo en relación a la literatura médica, las ventajas de lo digital son mucho más evidentes y hacía ver también su preocupación, sobre si hay algún requisito específico para una eventual indexación futura.

- Finalmente, otro destacado miembro de la "subsetenta-sesenta" concordaba con los obsoletos: "creo que la Revista Chilena de Anestesia debe seguir $\mathrm{y}$, un argumento que se me ocurre, es mirar a otras latitudes y hasta donde yo sé en el mundo las Revistas prestigiosas siguen editándose. Mi romántico amigo olvidaba que la nuestra ni siquiera cumple los requisitos para estar indexada en SciELO (Scientific electronic library online) y no tiene ningún prestigio.

Hasta aquí todo coincidía más o menos con mi hipótesis, sin embargo, la guinda de la torta la puso el Dr. Jorge Dagnino (dije que iba a ser un resumen "casi" anónimo). Esto lo digo porque contaba con que el Dr. Dagnino iba a ser un asiduo partidario de la versión física. Además de tratarse del más 
obsoleto de los recurridos (aunque el tal Urzúa me gana), como el mismo se autodefinió, me consta que tiene empastados todos los números de la Revista, excepto uno, tras el cual ha recorrido cielo, mar y tierra. Sin embargo, su opinión fue lapidaria, con una visión moderna y actual, que me da una dura lección de vigencia:

- La marea es irresistible. Me parece se han planteado, y muy bien, los principales aspectos de un cambio hacia lo digital: los positivos y los negativos. Sin abundar, dos consideraciones:

1) Agilidad de la publicación digital apenas aprobado el manuscrito final por los autores, sin tener que esperar un cierto número de páginas antes de imprimir y repartir la revista.

2) Posibilidad de discusión oportuna de un trabajo lo que, a lo menos en teoría, mejoraría el intercambio de ideas y el interés de la revista. $\mathrm{Y}$ dos precauciones:

1) El sitio web que maneje la revista debe ser lo suficientemente ágil y dúctil como para permitir una revista digital que valga la pena y entusiasme. Una reciente experiencia personal me enseñó que algunas prestigiosas empresas del rubro no tienen ni la experiencia ni las herramientas para hacerlo.

2) El respaldo de la revista debe ceñirse a estándares estrictos que aseguren que no se perderá todo cuando se corte la luz (algo que los agoreros nos pronostican será frecuente).

De este modo, aunque yo esperaba esa división de opiniones entre adultos mayores y adultos menores, casi todos están de acuerdo en que el camino hacia lo digital es inevitable.

Hace unos 6 años tuve una discusión (conversación) con mi hijo sobre el futuro del libro (el libro libro, como el café café). Le hablé de la textura y del olor del papel y de una serie de cosas que ahora con mi Kindle no siento. El hecho es que es una irrefutable realidad que el bendito dispositivo me ha permitido leer más que nunca.

Creo que seré el editor que se convertirá en el enterrador de la versión física de nuestra revista. Me he puesto este año de meta para que otros hagan lo inevitable, sin embargo, sigo teniendo dudas. Creo que hay una opción intermedia que debe ser considerada. La convivencia de ambos formatos, con una subscripción aparte (a pesar de que la Revista siempre se planteó como uno de los atractivos de pertenecer a la Sociedad). Actualmente existe la tecnología para sacar un bajo tiraje de la revista, con un número de ejemplares distinto para cada número, que dependa del número de inscritos. Es una opción que no es tan cara y es viable. También es una alternativa elegir un número de artículos seleccionados por el Consejo Editorial e imprimir un número al año.

El negocio no debe ser malo, y/o la revista tampoco es tan mala, porque la empresa de ediciones Elsevier, trató de contactarse con nosotros para tener una reunión, con el objetivo de manejar la edición impresa de la Revista Chilena de Anestesia. Este contacto ocurrió sin embargo, cuando las decisiones parecían estar tomadas.

La decisión de donde se invierten los dineros con que colaboran los laboratorios y empresas relacionadas depende exclusivamente de la Sociedad de Anestesiología. Si tienen más interés en invertir dinero en avisos en medios digitales, que no lo hagan en nuestra página web, pues lo único que hacen es contaminarla con propaganda y quitarle seriedad a un medio de difusión científica. Si no tienen interés en invertir en medios gráficos, los socios pagamos una cuota anual. ¿No alcanza? Habrá que adecuarla a los tiempos, pero tampoco poner la subscripción de la Revista como un incentivo a la inscripción en la Sociedad y luego quitárselo. En todo caso, no creo que esto último sea necesario. Período tras período vemos a los Presidentes rindiendo cuenta orgullosos sobre la capitalización efectuada durante su mandato. ¿Para qué queremos más dinero en la cuenta bancaria? ¿Por qué no usamos esa plata en docencia, en ayudar a la investigación, en extensión (incluida la Revista)? ¿O es muy tonto lo que estoy diciendo?

En fin, como lo que se viene es inevitable, de todas maneras creo que el pasar sólo a versión digital, debe ser realizado de la mejor manera. No es llegar y dejar de publicar la versión impresa. Debe ser un proceso lento, gradual, superpuesto y ordenado.

Por lo delicado del tema, me gustaría tener opiniones diversas, cartas al editor, pro/con y recibir como retroalimentación todo lo que pudiera ayudar a efectuar este proceso lo menos traumático posible. Esperamos sinceramente sus comentarios.

Saluda atentamente a Uds.

\section{Dr. Ricardo Bustamante Bozzo}

Editor 